\title{
Generic Communication Skills of History Teachers In Junior College And The Relationship With Student Achievement
}

\author{
Mohamad Saiful Akmal Hamid, Anuar Ahmad \\ Universiti Kebangsaan Malaysia, 43600 Bangi, Selangor.
}

\begin{abstract}
This study aims to identify the level of generic skills of communication adopted by history teacher in the teaching and learning of the subject of history and its relationship with student achievement. This survey study using questionnaire conducted on 120 students at the Junior Collegein Malaysia which selected samples intended. The data obtained will be analyzed using "Statistical Package for Social Science" (SPSS) version 17. The analysis of studies reported in the form of descriptive and inferential percentage, mean, $t$-test and correlation. The results showed that most of the generic skills that were master by the history teacher is skills in the application of technology in the P\&P. While a average skill is mastered skills in Culture and Individual. The implications of this study was contributed to teachers pedagogical and a sign that the history teacher has a duty and responsibility in the context of history teaching to improve student achievement. To ensure the goals are achieved, teachers must be equipped with knowledge of generic skills.
\end{abstract}

Keywords:- generic skills, mastery, achievement,acceptance.

\section{INTRODUCTION}

The effectiveness and success of an educational institution is highly dependent on the ability of teachers to implement teaching and learning quality. Leadership quality teacher in the classroom is a critical factor and determinant of the effectiveness of education. The direction of education in the future aims to produce students who are confident, productive, innovative and creative. It aims to produce citizens who can meet the needs of the job market, competitive, resilient, hungry for knowledge, international character and be a driving force of economic growth (PPK, 2001). Ahamad (2005) stated that the development and progress in education in the country urged the teachers to master a range of generic skills, such as thinking skills, using and integrating information and communication technologies.

In Malaysia, the concept of generic skills has been introduced by the Ministry of Education in various subjects and programs (PPK, 1999). This change is necessary because any change that occurs is to provide a form of quality education and meaningful to students. For example, the National Education Philosophy drafted aims to produce citizens who are knowledgeable and competent, honorable, responsible and capable of achieving well-being and contribute to the betterment of the country (Abu Bakar and Ikhsan, 2003).

Generic skills to students who want to apply must be considered to be relevant, useful and durable and can strengthen the education system in order to be able to be fundamental to support lifelong learning (Mohd Safarin \& Kamaruddin, 2004). According to them again, generic skills should be beneficial and important for the students involved in all career fields and meet the needs of today's employers. These skills are needed by all sectors to be developed and assessed. These skills are needed by all sectors to make students and staff more effective and efficient (Rodiah, Siti Rahayah \& Noriah, 2008).

Generic skills is a skill that must be mastered by teachers in Malaysia. With a high generic skills, teaching and learning process is assumed to be implemented effectively, especially in achieving the goals and objectives of education. This is consistent with the fact that effective teaching is central to human capital formation. Thus, the generic skills should be implemented as early as possible including during the teachers programs. Generic skills become an important element in producing potential qualified teachers. Excellent academic results is not sufficient to be a competent teacher, then it should have prospective teachers with a good command of all the elements in this generic skills (Fariiqul Mohd Amin, 2009).

When attending teaching training program, teachers not only teach in the classroom, but they are also exposed to other skills that can be acquired outside the classroom. Skills named generic skills is important so that teachers can adapt quickly and be able to deal with challenges in the workplace (Vee Lynn Khoo, 2008). Their opportunities to improve generic skills are wide open and should be used by them in building a self-made personality. Covering generic skills element of communication skills, teamwork, problem solving skills, adaptability, lifelong learning, self-satisfaction and ethics are important elements (Rozanis, 2006). Therefore, it is desirable if the study was done to identify the level of generic skills of communication of History teachers in school. 


\section{LITERATURE STUDIESDOMESTIC STUDY}

A study conducted by Zamri Mahamod, Anisah Alias and Nur Ehsan Mohd Said (2012) to 127 students related to comparison of Generic Skills Student Option Malay done in an Institute of Higher Learning (IPTA) and the Institute of Teacher Education Malaysia (RRIM).Researchers have found that generic skills are more dominated by university students compared IPGM comprising communication skills, leadership and teamwork. As a result, researchers have been very useful in identifying the differences between generic skills option Malay students at public and IPG. Therefore, students in IPGM should further enhance the three generic skills within them.

While it can be seen also from the study conducted by Rodiah Idris, Siti Noriah Rahayah Ariffin and Mohd Ishak (2009) to 1262 undergraduates in Universiti Kebangsaan Malaysia (UKM) in relation to the effect of Generic Skills Critical Thinking Skills, Problem Solving and Communication Students. Researchers have found that significantly influence the generic skills of leadership skills in terms of generating ideas and often interact in a short time is an indication of the main causes of students proficient in communicating SMEs. In addition, lifelong learning skills or learning ability of all time is also an indicator of the main causes of students proficient in critical thinking and problem solving.

\section{STUDY ABROAD}

The literature review found that there was a correlation between the learning environment with learning approach. Previous studies by the researchers found that the construct of tasks related to the approach surface (Kember \& Leung 1998; Lizzio et al, 2002; Karagiannopoulou \& Christodolides 2005). Construct assessment (Kim 2002; Gijbel \& Dochy 2006; Kember, Leung \& Ma, 2007; Karagiannopoulou \& Christodoulides 2005). Construct good teaching (Kember \& Kam 2000; Ramsden, Prosser, Trigwell \& Martin, 2007; Cabrera, Colbeck \& Terenzini 2001; Karagiannopoulou \& Christodoulides 2005) also had a significant positive correlation with depth approach. While constructs evaluation, clear objectives, good teaching is studied by researchers West (Lizzio et al, 2002; Neto, Pallesen, Borland \& Larsen, 2006; Kim 2002; Wilson \& Fowler, 2005; Nijhuis, Segers \& Gijselaers 2008) found constructs has a negative correlation with surface approach and positive relationship with depth approach.

Past studies have found that good teaching, clear objectives and evaluation has a negative relationship with the surface approach (Goh, 2005). While deep in his study approach was found to have a positive relationship with clear objectives and a good lesson. Study of Trigwell and Ashwin (2006) found a significant relationship between teaching construct a good, clear objectives, assessment and load assignments with learning approach. While Chapman study, Ramondt and Smiley (2005) and Karagiannopoulou \& Christodoulides (2005) found that the relationship between learning community with in depth approach. In their study of the increasingly close relations in the community can enhance deep learning approach.

\section{RESEARCH OBJECTIVE}

In particular, the objectives of this study were to:

1. Identify the generic skills of communication as a whole that is dominated by a History teacher.

2. Identify the difference generic skills of communication with the History teacher acceptance of students in terms of gender.

3. Identify the generic skills of communication links History teacher to student achievement.

\section{RESEARCH METHODOLOGY}

\section{Research design}

Based on the objectives and research questions, design researchers use descriptive survey method. Descriptive study aimed to identify and report what is actually happening (Mohd Majid, 2005). Wiersma (1995) support by saying that the study can give a descriptive or information about a situation at a particular time. This design is suitable for use in data collection due to its scientific, logical and can investigate the relationship between the variables of the sample crowded (Borg and Gall, 1983). Descriptive study help make plans for the future. This design is suitable for use in this study because this study is that the information is valid and can be used to solve problems related to the future.

\section{SAMPLE SELECTION}


Sampling is a process of selecting a group of individuals for a study of a group of individuals who represent a large group of selected (Noraini, 2010). Sampling selected in this study consists of the college students. In this study, researchers took 120 students study. According to Goh (2005), a sample of students who are mature and experienced in teaching is appropriate to describe the experience of studying in educational institutions in accordance with the questionnaire used.

\section{RESEARCH INSTRUMENT}

To collect the necessary data, questionnaires were used. According to Mohd Majid (2005), a questionnaire is a measuring instrument used in educational research. The questionnaire is one of the easiest ways to obtain information and have more advantages compared to other ways in order to obtain quantitative information (Solomon, 2002). The use of questionnaires and responses form a closed item selected is very good because it does not require the subject or produce new ideas to a question (Kelringer, 1986). The questionnaire has four powers in conducting the study which is easy to manipulate and categorize the data to analyze, manage and govern data with efficient, easy to make generalizations, easy to analyze, test and make triangulation. Thus, in this quantitative descriptive study, the measuring instrument used was a set of questionnaire consists of eight parts according to attributes construct a generic communication skills.

\section{DATA ANALYSIS}

The data analysis was conducted after the data from the questionnaires were analyzed and quantitative analysis of the data generated. Data collected through the instruments of the A and B by the researchers analyzed using Statistical Package For Social Science (SPSS) Version 17 of the mean and percentage for each item questionnaire. Data were analyzed to help researchers evaluate and compare accordingly based research objectives. In this study, descriptive statistics such as mean and percent used.

The respondents comprised of students from different backgrounds. The method used is a survey method using questionnaires. The location of this research is the junior colleges. In this study, a questionnaire used consisted of 40 items where the items are divided into the following elements in eight major subkonstruk under the generic skills of communication are built. The element consists of eight main criteria. This item is divided as shown in Table 3.4.1 below:

Table 3.4.1: Elements of the Generic Skills Subkonstruk Communications

\begin{tabular}{|c|c|}
\hline Eight Elements of Generic Skills Communication Subkonstruk & Item \\
\hline $\begin{array}{l}\text { 1. Ability to presentation of ideas clearly, effectively and with confidence } \\
\text { orally and in writing. }\end{array}$ & 1 to 5 \\
\hline 2. Ability to practice active listening skills and provide feedback. & 6 to 10 \\
\hline $\begin{array}{l}\text { 3. Ability to make presentations clearly with confidence and in accordance } \\
\text { with the listener. }\end{array}$ & 11 to 15 \\
\hline 4. Ability to use technology in the presentation. & 16 to 20 \\
\hline 5. The ability to negotiate and reach an agreement. & 21 to 25 \\
\hline $\begin{array}{l}\text { 6. Ability to communicate with participants communicating with a different } \\
\text { culture. }\end{array}$ & 26 to 30 \\
\hline 7. The ability to develop interpersonal communication skills. & 31 to 35 \\
\hline 8. $\quad$ Skills in using non-verbal skills. & 35 to 40 \\
\hline
\end{tabular}

Questionnaire in this study requires respondents to select one of a score based on the instructions. Fivepoint Likert scale was chosen because of the high reliability and allow a lot of options to the respondent to make the right choice (Mohd Majid, 2005). Five-point Likert scale was used to obtain data for Part B. 1 Score used to scale Strongly Disagree, score two for scale Disagree, scoring three of the scale Less Agree, score four to five scale scores Agree and Strongly Agree to scale. Researchers then categorized the classification of a Likert scale of five points to seven levels. Its objective is to classify each item to certain levels to enable a clearer analysis and meaningful. Each construct after this will be stated briefly that, Presentation of Ideas, Listening, Presentations, Technology, Negotiate, Culture, Individual and Non-Verbal. 


\section{FINDINGS}

The researchers will present the results of the analysis of data obtained from the survey respondents consisting of boys and girls in the junior college with 120 students in Malaysia. The findings of this study has used statistical data analysis which involves score to see score level generic skills teacher communication history and its impact on student achievement overall. In addition, inferential statistical analysis t-test was used to identify differences in the generic skills of communication with the History teacher acceptance of students in terms of gender. Therefore, the statistical analysis in this chapter has also been using correlation analysis to identify the generic skills of communication links History teacher to student achievement.

\section{DESCRIPTIVE STATISTICS}

The Mean Score of Each Construct Generic Skills Communication

The findings obtained from the analysis of data generated showed mean scores of each generic skills teacher communication history with each other based on Table 4.2.4.1. It can be seen from the mean scores generic skills of communication history teacher most is Technology (4:48) and was followed by the Presentation (4.38), Listening (4:31), Presentation of Idea (4.27), Negotiate (4.09), Non-Verbal (3.75). While the generic skills of communication Single (3.30) and culture (3.23) were at a moderate level.

Table 4.2.4.1: Generic Skills Communication Mastery Mean Score History Teachers Overall

\begin{tabular}{lll}
\hline Generic skills Communication & $\mathrm{N}$ & Mean \\
\hline Presentation of Ideas & 120 & $4: 27$ \\
Listening & 120 & 4.31 \\
Presentation & 120 & 4.38 \\
Technology & 120 & $4: 48$ \\
Negotiating & 120 & $4: 09$ \\
Culture & 120 & 3.23 \\
Individuals & 120 & 3.30 \\
Oral & 120 & 3.75 \\
\hline
\end{tabular}

The results obtained from the mean score for each level of generic skills teacher communication history can be seen from all the generic skills that are in high and medium level based on mean scores obtained. It shows no mean score was at its lowest level should be seen in the interpretation of the real score.

\section{Mean Score Generic Skills Mastery Level Communications History in the Overall Master Subjects} History

The results of the findings are the first to answer the question of generic skills of communication as a whole is dominated by a history teacher is the most dominant and less dominant. Therefore, the results obtained from this study have shown that generic skills of communication, the most dominant is dominated by a history teacher skills in technology with a score of 4:48 min. It can be seen from Table 4.2.5.1 that mean score of generic skills of communication in terms of the dominant technology in the Junior College.

Table 4.2.5.1: Mean scores in the overall Subjects History Based Communication Mastery Generic Skills Teacher

\begin{tabular}{lll}
\hline Number of Respondents & Generic Skills Communication & Mean \\
\hline 120 & Technology & $4: 48$ \\
\hline
\end{tabular}

In addition, to answer the second research question, namely generic communication skills as a whole that is dominated by a history teacher who is the dominant medium of cultural aspects with a mean score of 3.23, which is at a moderate level. It can be seen from Table 4.2.5.2 below shows the mean scores of generic skills of communication in terms of a simple dominant culture in the junior college.

Table 4.2.5.2: Mean scores in the overall Subjects History Based Communication Mastery Generic Skills Teacher

\begin{tabular}{lll}
\hline Number of Respondents & Generic Skills Communication & Mean \\
\hline 120 & Culture & 3.23 \\
\hline
\end{tabular}

Analysis Of Inferential Statistics

T-test Analysis Independent Difference Against Generic Skills Communication History Teacher With Student Acceptance By Gender 
Table 4.3.1.1: T-test analysis Not Lean Against The difference Min Generic Skills Communication History Teacher With Student Acceptance By Gender

\begin{tabular}{lllccc}
\hline Gender & Generic Skills & Mean & Standard Deviation & T & Sig. \\
\hline Male & Technology & 4.49 & .30460 & .277 & .250 \\
Female & Technology & 4.47 & .35313 & &
\end{tabular}

Based on Table 4.3.1.1 above, which shows that the mean of generic skills that dominated history teacher and student admission based on gender can be seen from the generic skills of communication and technology aspects of male students is $4: 49 \min (\mathrm{N}=60, \mathrm{SD}=.30460)$. While it can be seen also from the mean of the generic skills of communication technology that is dominated by a history teacher and student enrollment by women is 4:47 $(\mathrm{N}=60, \mathrm{SD}=.35313)$. This indicates acceptance by students based on what their teachers are employed by the same or not materially different even if there is little difference between the sexes.

In addition, the results of the statistical analysis t-test showed no significant difference between generic skills that are dominated by a history teacher and student admission based on gender, namely $(\mathrm{t}=.277, \mathrm{df}=118$, p> 0.05). Therefore, the results of this analysis show that the null hypothesis is accepted $\left(\mathrm{Ho}_{1}\right)$ and indirectly no difference in mean generic skills mastered by a significant history teacher by the reception of students based on gender. Although researchers have found differences in the mean score (0.16) for males and females, but the difference is still unable to reject the null hypothesis.

\section{Pearson Correlation Analysis Generic Skills Relationship History Teachers Communication with Students Achievements}

Table 4.3.2.1: Power Relations By Value Correlation

\begin{tabular}{cc}
\hline Correlation Index Value & Interpretation Relations \\
\hline $0: 00-0: 20$ & Very Poor \\
$0: 21-0: 40$ & Poor \\
$0.41-0.70$ & Medium \\
$0.71-0.90$ & High \\
$0.91-1.00$ & Very High \\
\hline
\end{tabular}

Table 4.3.2.2: Pearson Relations Generic Communication Skills of History Teacher With Student Achievement

\begin{tabular}{llll}
\hline Relationship & \multicolumn{2}{c}{ Achievement } & Interpretation \\
\cline { 2 - 3 } & $\mathrm{r}$ & Sig. & \\
\hline Presentation of Ideas Skills & .004 & .965 & Very weak \\
Listening Skills & -.047 & .613 & Very weak \\
Presentation Skills & -.060 & .514 & Very weak \\
Technology Skills & -.041 & .657 & Very weak \\
Negotiating Skills & .027 & .771 & Very weak \\
Culture Skills & .168 & .067 & Very weak \\
Individuals Skills & .083 & .368 & Very weak \\
Non-Verbal Skills & -.060 & .516 & Very weak \\
\hline
\end{tabular}

Table 4.3.2.2 above indicate that there is no significant relationship between generic skills of communication aspects Presentation of Ideas, History teachers with exam scores on student achievement that can be seen from the value $r=.004$ and $\mathrm{sig}=(\mathrm{p}>0.05)$. This indicates that the null hypothesis is accepted $\left(\mathrm{Ho}_{2}\right)$ there is no significant relationship between generic skills in aspects of communication Presentation History teachers with exam scores of students are accepted.

Moreover, it can be seen also from the generic communication skills teacher History of the Hearing with exam scores on student achievement that can be seen from the value $r=-.047$ and $\operatorname{sig}=(p>0.05)$. This indicates that the null hypothesis is accepted $\left(\mathrm{Ho}_{2}\right)$ there is no significant relationship between teachers' generic skills of communication in history with many aspects Hearing exams on student achievement is acceptable.

Generic skills teacher communication history of the Presentation of the exam scores on student achievement that can be seen from the value $r=-.060$ and $\operatorname{sig}=(p>0.05)$. This indicates that the null hypothesis is accepted $\left(\mathrm{Ho}_{2}\right)$ there is no significant relationship between generic skills of communication in terms of presentation of history teachers with exam scores of students are accepted. 
Generic skills teacher communication aspects History of Technology with exam scores on student achievement that can be seen from the value $r=-.041$ and $\operatorname{sig}=(p>0.05)$. This indicates that the null hypothesis is accepted $\left(\mathrm{Ho}_{2}\right)$ there is no significant relationship between generic skills of communication in terms of history teachers with exam scores of students are accepted.

Generic skills of communication teacher History of aspects Consult with exam scores on student achievement that can be seen from the value $r=.027$ and $\operatorname{sig}=(p>0.05)$. This indicates that the null hypothesis is accepted $\left(\mathrm{Ho}_{2}\right)$ there is no significant relationship between generic skills in aspects of history teacher communication Negotiate with exam scores on student achievement is acceptable.

Generic skills of communication teacher History of Culture with the exam scores on student achievement that can be seen from the value $r=.168$ and $\operatorname{sig}=(p>0.05)$. This indicates that the null hypothesis is accepted $\left(\mathrm{Ho}_{2}\right)$ there is no significant relationship between teachers' generic skills of communication in terms of culture and history exam scores of students are accepted.

Generic skills of communication teacher History of Individual aspects of the exam scores on student achievement that can be seen from the value $r=.083$ and $\operatorname{sig}=(p>0.05)$. This indicates that the null hypothesis is accepted $\left(\mathrm{Ho}_{2}\right)$ there is no significant relationship between teachers' generic skills of communication in terms of natural history and exam scores of students are accepted.

Generic skills of communication teacher History of Non-Verbal aspect with exam scores on student achievement that can be seen from the value $r=-.060$ and $\operatorname{sig}=(p>0.05)$. This indicates that the null hypothesis is accepted $\left(\mathrm{Ho}_{2}\right)$ there is no significant relationship between generic skills of communication in terms of history teachers with Non Verbal exam scores of students are accepted.

\section{DISCUSSION}

\section{Generic Skills Mastery Level Communications History in the Overall Master Subjects History}

Based on the findings of opinion and perception of students, found overall history teacher's at the college have high generic skills level of communication. The analysis showed six types of generic skills of communication controlled by a history teacher at the high level and the other two are at a moderate level. It shows students the impression that they are a history teacher generic communication skills during the process of learning.

The first generic communication skills are at a high level is a technology with a mean score of 4:48. It shows students the impression that they are a history teacher really skilled and master the technological aspects during the process of learning. History teacher mastery in aspects of this technology will ensure the information presented is interesting and persuasive and presentation of the information can be conveyed accurately. Most of the respondents involved in this study stated that their history teachers can impress them by showing clear visual and are able to apply these skills during the teaching and learning.

Both generic communication skills are at a high level is a presentation by the mean score of 4:38. This situation shows the students the impression that they are a history teacher really skilled and mastering presentation aspects during the process of learning. History teacher mastery in aspects of this presentation will be to make sure the subject is taught can be readily understood by students. Most of the respondents involved in this study will be noted that a history teacher they are able to answer any questions related to the presentation that was made, intelligent control the tone of voice in teaching, confident and enthusiastic when teaching about a topic, taught according to ability and level of the students and listeners active and give feedback on the students' answers.Generic skills-party communications are at high level is a hearing with the mean score of 4.31. This situation shows the students the impression that they are a history teacher really sensitive to hear during the course of the process of learning. History teachers always listen actively will easily provide feedback and easily find compatibility with the new student overheard the conversation known and always respond positively to every question asked by students. This causes the students assumed that the teachers give care and consider any issues raised by the students is important and should be given attention.

The fourth communication generic skills are at high level is a Presentation of Ideaswith the mean score of 4.27. This situation shows the students the impression that they are a history teacher really skilled and controlled delivery aspects during the process of learning. History teacher proficiency in the delivery aspect will make an idea can be conveyed clearly, effectively and with confidence whether orally or in writing. The students thought their history teacher looks confident and comfortable while speaking with students, can detect facial feelings to see the students clearly and effectively and is able to give ideas and advice for students to progress in academic writing or orally.

In addition, the analysis showed that the five generic skills are at a high level is in talks with the mean score of 4:09. This shows that the students thought that their history teachers always be open to the concept of consultation to reach consensus or agreement on certain issues or matters arising or raised. This situation shows that history teachers they practice the concept of 'laissez faire' to give students the freedom to express opinions 
or views in order to obtain brilliant results and quality during the process of negotiation between teachers and students took place. Therefore, most of the respondents involved in the survey said they were able to teach history to consider a matter fairly and impartially during the consultation process to take place.

In addition, the analysis shows that the six generic skills are at a high level is a Non-Verbal with the mean score of 3.75. This shows that the students thought that their history teachers can use non-verbal skills during the process of learning. This situation shows that apart from verbal skills in terms of the tone of voice, their history teacher is also able to take advantage of the force of their bodies in attracting students. Most respondents said that things become a teacher bonuses or advantages to their history of being able to attract or humorous to a situation and atmosphere.

In addition, the analysis also shows that there are generic skills that are at a moderate level of singles with the mean score of 3.30. This shows that the students thought that their history teachers in terms of individual communications as a teacher is able to convey feelings, emotions, confidence and honesty while teaching. In addition, they also treat their teachers are able to adjust the language and presentation while teaching, intelligent praise, encouragement and correcting errors, able to communicate well with students of different races and cultures and be able to give feedback and understanding in giving answers that were by student's.

In addition, the analysis also shows that there are generic skills that are at the level of the culture medium with a mean score of 3.23. This shows the students assume their history teachers seldom emphasize the cultural aspects during the process of learning. It is also driven by the absence of other races besides students in the college's. Therefore, based on the questionnaire, the students thought that things were not relevant to the situation prevailing in their schools. In the context of implementing the various elements of this culture, teachers need to have skills in explaining to the students that the culture that you can practice and culture that can not be used and provide an explanation of why culture may or may not be practiced. Thus, in such cases, teachers should use wisdom to approach the cultural values and traditions can be readily understood by students.

\section{GENERIC SKILLS COMMUNICATION HISTORY TEACHER WITH STUDENT ACCEPTANCE BY GENDER}

Ho2 results of this study are examined using t-test and the overall findings of this study showed no significant difference in acceptance between boys and girls on the generic skills of communication controlled by their history teacher. This means, their history teacher who uses the generic skills of communication anywhere in the teaching and learning is still acceptable to boys and girls and increase their performance in the examination.

\section{RELATIONSHIP BETWEEN HISTORY TEACHERS COMMUNICATION GENERIC SKILLS AND STUDENTS ACHIEVEMENTS}

Azam (2007), in his study on the level of generic skills in teaching engineering technical school in Kelantan and Terengganu have found that teachers are aware of the importance of generic skills. These generic skills, especially in the aspect of communication is important for students to produce and provide an efficient work, competent, and thus can contribute in the workplace. Form 4 Junior Collegestudents assume generic communication skills History teachers are important to them and increase their performance. These findings parallel studies conducted by Rashid and Yahya (2003). In the study, they found that communication skills is one aspect that is considered important by the teaching staff of the Institute of Agricultural Vocational Training.

Nowadays, technology has advanced and sophisticated computer and the college students considers teachers' ability to use the technology in teaching and learning is important, and so on. This can be proved that through the studies that have been conducted, the generic skills of communication in terms of ease of use of technology by teachers is the highest mean score. These findings are supported by a study conducted by Hazilah et. al (2002) who found skills in the use of technology such as computers is an important skill to master by preparing students for the world of work. Therefore, teachers or teacher must serve to integrate technology, especially computer skills to students so that they are more confident to master it well.

Next, the college student also consider the ability of generic skills teachers in Presentation of Ideas is an important aspect and increase their performance. This can be proved that through the studies that have been conducted, the generic skills of communication in terms of the presentation by the teacher is the second highest mean score. This is supported by a study conducted by Siti Zaleha et. al (2007) which states communication skills presentation is important, especially in terms of presentation of the report, written report, mempengurusikan receptions, meetings and sebagaianya indispensable in the field of employment compared to the skills that are more specific to a field that can be obtained through training such as 'on the job training'.

The college students high awareness of teachers in active listening skills during the process of teaching and learning driven by a strong motivation in the teacher himself. Teachers have a strong self-confidence and 
this will help students to improve their achievement. Sharifah Akmam (2005), explained that if a person believes that he can do a job is difficult, then he can actually do it. This is proven by the results of a study conducted generic skills of communication in terms of Hearing by the teacher is the third highest mean score. The researcher believes mastering the skills of listening well is driven by a high level of awareness of teachers of these skills. Teachers concentrate on hearing and be able to respond appropriately when communicating with students.A good listener will think more broadly as they listen and understand more facts and viewpoints. According to Zulkifli Yusof (2000), heard that communication is an important aspect. Active listening and practice will improve the effectiveness of communication between people.

Furthermore, the college student also assumes that the ability of generic skills in aspects of their history teachers is high and idea presentation skills and increase their performance. This is proven by the results of a study conducted in the generic skills of communication Presentation is the fourth highest mean score. The researcher believes that the ability of teachers to communicate ideas clearly, effectively and with confidence orally and in writing to improve student achievement.This is in line with what was stated by Shahabuddin Hashim et. al (2003) presentation aspects to be considered in communication skills so that the message delivered is acceptable and well understood.

In addition, the findings showed that most students give consent that their history teachers to apply generic skills in aspects Negotiate or talk. The case is said to be able to improve the skills of self in the process of discussion or negotiation. This situation can be proved through the research conducted lakes generic skills of communication in the consultation is the fifth highest mean score. This is consistent with a study conducted by Abd Ghafar (2003) that said method is a method of negotiation or discussion of interest in which is divided into two, namely formal and informal discussions. Through negotiations, the teachers and their students to each other are trained to listen and accept the views of others and equally to design something or make a decision. Teachers need to use the engagement to dominate generic skills as it's an interesting method. This case is also supported by Noraini et. al (2003) who said vocational teachers agreed teaching and learning based on research and consultation methods to integrate disposable skills. This finding also supports research by Abel (2002), Gutteridge (2004), Muir (2004) and Somerser (2001) who argues that must master the skills of effective communication and consultation to achieve the discussions are ongoing.

Furthermore, the college student also assumes that the ability of generic skills in aspects of their history teachers Non-Verbal skills are high and increase their performance. This is proven by the results of a study conducted generic skills of communication in terms of delivery is the sixth highest mean score. Mastery of these skills will lead teachers to understand their students are able to create an effective classroom environment, choose tugassan-appropriate tasks and preserve the level of students' motivation to learn and accept the simple methods of non-verbal skills used by the teacher. The results were positive for the category of non-verbal communication is very encouraging because it is one of the characteristics of teacher quality and high integrity as master interpersonal communication skills or competence (DeVito, 2002). This is also consistent with studies Abd. Rahman (1996) stating that the communication in the classroom can occur verbally and nonverbally. This is because in teaching, teachers interact with students to talk, member of clarification, questioning, sturdy, rebuke, pointing, gesturing, approaching students, impose fines and so on. This means that even if we stop talking, we did not stop for non-verbal signals such as physical appearance, movements and eye contact. Similarly, in the process of learning, every behavior and gestures between teachers and students is a form of communication that is not visible.

The college students assume that the ability of generic skills in aspects of their history teacher Individual communication is both the lowest even at the level of a simple mean score in this study. Although researchers have to explain a little about this aspect of interpersonal skills to students that are specifically geared to the situation of a teacher is to give a reaction or response. The situation seems to give the impression that the students still do not understand the issues raised in the questionnaire during the circulation process questionnaires carried out. Thus, the history teachers need to continue to develop communication skills, particularly in terms of delivering emotion, language adjustments, bonus praise, and feedback accurate, concise and easily understood by students. The study is also consistent with the findings in the study by Quek (2005) who found that the skills of individuals and cognitive skills needed for effectiveness in doing a job.

The college students assume that the ability of generic skills in aspects of their history teacher in Culture was the lowest even at the level of a simple mean score in this study to improve their performance. This is because, due to all the students in the college showed their lack of understanding about the research questions raised in the cultural aspects of the questionnaire were distributed. Although researchers have to explain a little about the subject, the students seemed still show less understand and appreciate the value of cultural aspects as has been explained to them. Therefore, history teachers need to be implemented or emphasize the cultural aspects in teaching and learning so that students can understand, appreciate and practice values such as considerate, tolerant, respectful, responsible and mutually helping each other in creating dots intimacy and close ties between people of all races and nations (Mohd Mahzan et. al 2016a, 2016b). 


\section{CONCLUSION}

Based on the overall results of the study show the positive aspects for teachers to master well any generic skills. Generic skills should be emphasized in order to produce human capital that can meet the needs of the country. Therefore, teachers need to master generic skills among them. Implementation and application of generic skills are not just limited to seven generic skills that have been studied and generic skills is very important for every teacher of history are the focus of this study.The aim of this study can give exposure to the teacher in the case of generic skills among History teacher at the school, in addition to establishing the characteristics of teachers who will be competent not only in teaching, but also other aspects, particularly in relation to generic skills.

\section{REFERENCES}

[1] Aini Hussain, Che Husna Azhari, Dzuraidah Abdul Wahab, Isaac \& Siti Noriah Rahaya Ariffin, 2005, Application of Generic Skills in Teaching Using Tersebati, Seminar on Effective Teaching and Learning, Universiti Kebangsaan Malaysia, Bangi, p. 129-145.

[2] Ahmad Johari Sihes \& Azwanee Siti Abdullah, Practices Generic Skills Learning among Students in Year Four, Faculty of Education, Universiti Teknologi Malaysia.

[3] Azwani Bin Ismail, Aziz Zahara, Sharifah Nor Puteh \& Abdul Razaq Ahmad, Effect Model Student Team Achievement Division (STAD) and Communication Skills Students In Subjects History, National University of Malaysia.

[4] Jumaatol Halisha Binti Bujang, 2006, Study Use of Generic Skills In the process of teaching and learning in schools , Exercise Science, Universiti Teknologi Malaysia, p. 1-9.

[5] Lue, LP Irene, Baharuddin Aris, Zaidatun Tasir, A Pilot Study On Detection Generic Skills Students Who Have Dominated by the Active Learning University, $1{ }^{\text {st }}$ International Malaysian Educational Technology Convention, Faculty of Education, UTM Skudai, p. 410-422.

[6] Fathi Bin Mohd Adnan, 2013, Application of Generic Skills in Teaching Teachers Technical and Vocational Education (TVE) in Vocational Special Education Secondary School (SMPKV) in Malaysia, Exercise Science, Faculty of Education, Universiti Teknologi Malaysia.

[7] Hj Mohd Safiee. Idris Hj. Ashari Sikor, Zahara Siti Binti Mohd Ariff Mohd Zaid Mustafa, Ahmad Rizal Madar \& Latifah Md. Ariffin, 2008, Interpersonal Communication in Teaching Among Teachers Secondary Technical School of Engineering in Melaka, National Student Development Conference in Universiti Teknologi Malaysia, 22-23 October 2008, Faculty of Education, Universiti Tun Hussein Onn Malaysia.

[8] Mohd Salleh Abu, deeply regrets Kamaruddin Ibrahim, Zainudin Abu Bakar Mohd Ali Ibrahim, Megat Megat Zaahiri Safe \& Muhammad Abd Hadi Zakaria brother, Mastering Soft Skills Trainer In kalngan Teachers, faculty of education, p. 1-10.

[9] Muhammad Faizal Bin A. Ghani \& Rosnah Binti Ishak, 2003, Practice Learning Among Teachers High Performance Schools, Juku: Journal of Curriculum \& Teaching Asia Pacific, Department of Policy Planning and Management Education, Faculty of Education, Universiti Malaya, p. 52-60.

[10] Noraini Binti Mohd Noor \& Hung Hsien Yang, Possession Generic Skills Students 4SPH (Prime) To Setup enter the teaching profession in Subjects Life Skills, Faculty of Education, Universiti Teknologi Malaysia.

[11] Norhayati Binti Ahmad, 2010, Availability Deployment Generic Skills Teachers Technical Trainer During Teaching Practice, Exercise Science, Faculty of Education, Universiti Teknologi Malaysia, p.18.

[12] Rodiah Idris, Siti Rahayah Ariffin \& Noriah Mohd Ishak, 2009, Effects of Generic Skills in Krititikal Thinking Skills, Problem Solving and Communication Students of Universiti Kebangsaan Malaysia, MJLI VOL 6 (2009), Universiti Kebangsaan Malaysia, Bangi, p. 103-140

[13] Rozanis binti Mustapha, 2006, interest Geherik skills among Coming Educator, Case Study: Students in Years 4, Vocational Technical Education, Faculty of Education, UTM, p. 1-9.

[14] Sharifah Akmam Syed Zakaria, 2005, Guidelines and Strategies for Self Motivation, Kuala Lumpur, Utusan Publications \& Distributors Sdn. Bhd.

[15] Umi Madiha Mohd Nor, Zamri Mahamod \& Jamaludin Badusah,Application of Generic Skills in Teaching Secondary School Teachers Bahasa Melayu, Bahasa Melayu Journal of Education, Universiti Kebangsaan Malaysia, p. 71-84.

[16] Zamri Mahamod, Anisah Alias \& Nur Ehsan Mohd Said, Comparison of Generic Skills Option Malay Students at universities and IPG A, AJTLHE Vol. 4, No. 1, Jan 2012, 82-95, Universiti Kebangsaan Malaysia. 
[17] Mohd Mahzan Awang, Alfitri, Abdul Razaq Ahmad\& Norila La Ulu. (2016). Measuring Multi-Ethnic Students Citizenship Competence:Domains and Indicators. American Journal of Applied Sciences, 13 (1), 123-130

[18] Mohd Mahzan Awang, Abdul Razaq Ahmad, Noria Munirah Yakub, Ahmad Ali Seman. (2016). Historical Thinking Skills among Pre- Service Teachers in Indonesia and Malaysia. Creative Education. 7 (1), 62-76 